\title{
The INGVterremoti blog: a new communication tool to improve earthquake information during the Po Plain seismic sequence
}

\author{
Maurizio Pignone ${ }^{1}$, Concetta Nostro $^{1}$, Alessandro Amato ${ }^{1,}$, Emanuele Casarotti $^{2}$, Claudia Piromallo $^{2}$ \\ ${ }^{1}$ Istituto Nazionale di Geofisica e Vulcanologia, Centro Nazionale Terremoti, Italy \\ ${ }^{2}$ Istituto Nazionale di Geofisica e Vulcanologia, Sezione Roma 1, Roma, Italy
}

\author{
Article history \\ Received July 31, 2012; accepted September 7, 2012. \\ Subject classification: \\ Seismology, Educational, Public issues, Earthquakes, Seismic awareness, Seismic hazard.
}

\section{Introduction}

The INGV sites that deliver information in quasi-realtime are well known. People often connect to the INGV home page (www.ingvit), to the Centro Nazionale Terremoti (National Earthquake Centre) page (http:// cnt.rm.ingv.it) and to the Italian Seismic Instrumental and Parametric (ISIDe) database (http: / / iside.rm.ingvit) to obtain information about recent earthquakes. Moreover, people look for more specific and detailed information on the historical earthquake catalog (http://cpti11.mi.ingv.it), the seismic hazard web pages (http://zonesismiche.mi.ingv.it), the INGVterremoti YouTube channel (http:/ / youtube.com/ ingvterremoti), the web-based macroseismic survey (http:/ / www.haisentitoilterremoto.it/) and others. For all of these sites, some of which are reached by hundreds of thousands, or even millions people in cases of strong earthquakes, people can find a lot of specific information on individual earthquakes, on the seismic history, and so on. However, a place where people could find updates and explanations on the ongoing activity was not available. When the Po Plain seismic sequence started on May 20, 2012, through the enormous number of hits on the website of the INGV, to the many phone calls, emails and tweets, we soon realized that the request for information was huge. There were 0.61 and 0.93 million visits and 12 million and 26 million accesses on May 20 and 29, 2012, respectively. This was not a surprise, of course, because also during the L'Aquila 2009 sequence there was a similar situation. Indeed, in the months after the April 6, 2009, event, also through the installation of the Centro Operativo Emergenza Sismica (Seismic Emergency Operational Centre) in L'Aquila [Moretti et al. 2011], we understood that the request from the public and local authorities for complete and authoritative information was higher than had been previously thought. In particular, in the 2009 emergency, and even more so in the 2012 emergency, as well as classical information on web sites, many people looked for information and updates on social network sites. For this reason, between 2009 and 2011, the INGV started to test different social media, such as YouTube, Twitter, Facebook, and developed an application for the iPhone, to release earthquake information. Social media have proven to be very important for information sharing during crises [Earle et al. 2011, Bruns et al. 2012].

For all of these media, we observed relevant increases in the number of views and downloads corresponding to the important seismic events, when the attention was high [Amato et al. 2012, Nostro et al. 2012]. For this reason, in the days after the May 20, 2012, mainshock, we decided to open a new blog to provide quick updates and in-depth scientific information, such as articles on the ongoing seismic activity. Providing timely information is particularly important when seismic sequences last for several weeks and are characterized by several $M>5$ events, as was the case of the Po Plain earthquakes.

At the same time, we worked to provide fast, but scientifically sound, information, which was constantly updated and distributed throughout the territory, also to counter the bad information, and to fight rumors.

\section{The INGVterremoti blog}

The blog was created using the well-known WordPress platform (http://ingvterremoti.wordpress.com). WordPress.com is a free hosting platform that makes it easy for anyone to publish online. It is not necessary to download software or manage a web server. WordPress.com has hundreds of themes, that include many for functionality and for widgets. For our blog, we chose the 'Mystique' theme, a flexible theme that offers layout choices, many widgets, and support for social media. It was opened on May 21, 2012, initially for internal testing, and then open to the public on May 29, 2012. We decided not to allow comments on the blog, due to the huge amount of time needed to answer 


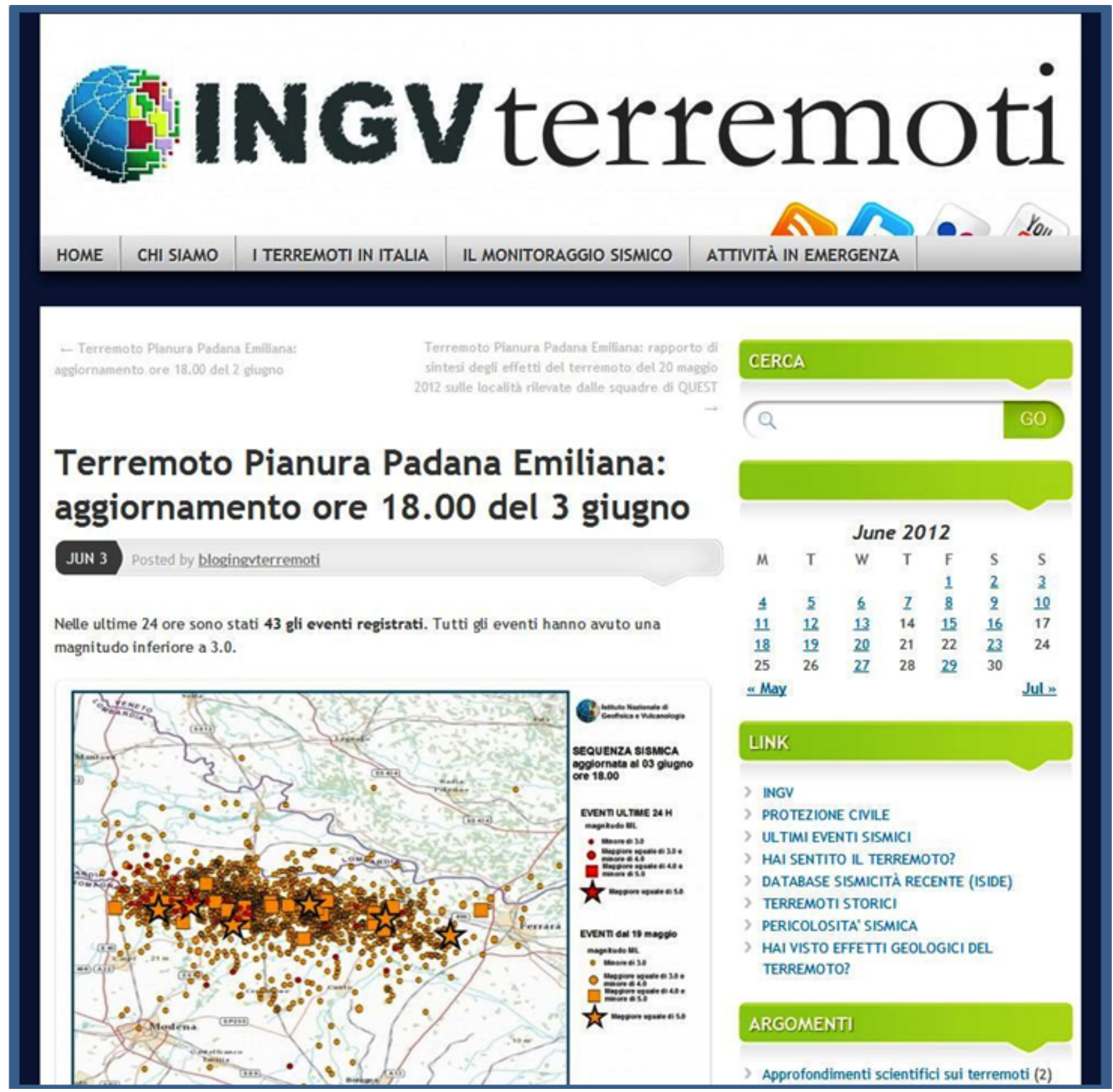

Figure 1. The top part of the INGVterremoti blog as it appeared on June 3, 2012, soon after the most clicked update was posted (857,785 clicks).

such questions and comments, which was not yet feasible for our present organization. It is our wish to open this section in the future.

The blog contains both static and dynamic pages, the latter being the predominant part. The static section includes pages about the INGV (Chi siamo/Who we are), earthquakes in Italy (I terremoti in Italia), seismic monitoring (Il monitoraggio sismico), and activities in an emergency (Attività in emergenza). Figure 1 shows the top part of the site, during the busiest day (June 3, 2012). The official language is Italian, as the blog is mostly devoted to people living in the Italian region. It is our wish to create an English section in the future.

The dynamic section contains mostly posts organized in different categories. For the Po Plain seismic sequence, we created a category named 'The Po Plain earthquakes in Emilia' (I terremoti della Pianura Padana Emiliana), with updates on the sequence, including, for example, maps, histograms, explanations, and videos. This part is divided into nine sub-categories, as given in Table 1.

In the two months after the start of the Po Plain seismic sequence, we published more than 80 posts about the sequence, to describe different activities carried out during the emergency, and the first scientific results obtained from preliminary data processing. As soon as better results were made available we promptly published in-depth articles. Moreover, in this time interval, some relevant earthquakes hit other regions of Italy, such as the May 28, 2012, $\mathrm{M}_{\mathrm{L}} 4.3$ seismic event close to Pollino (Calabria), the June $6, \mathrm{M}_{\mathrm{L}} 4.5$ seismic event 


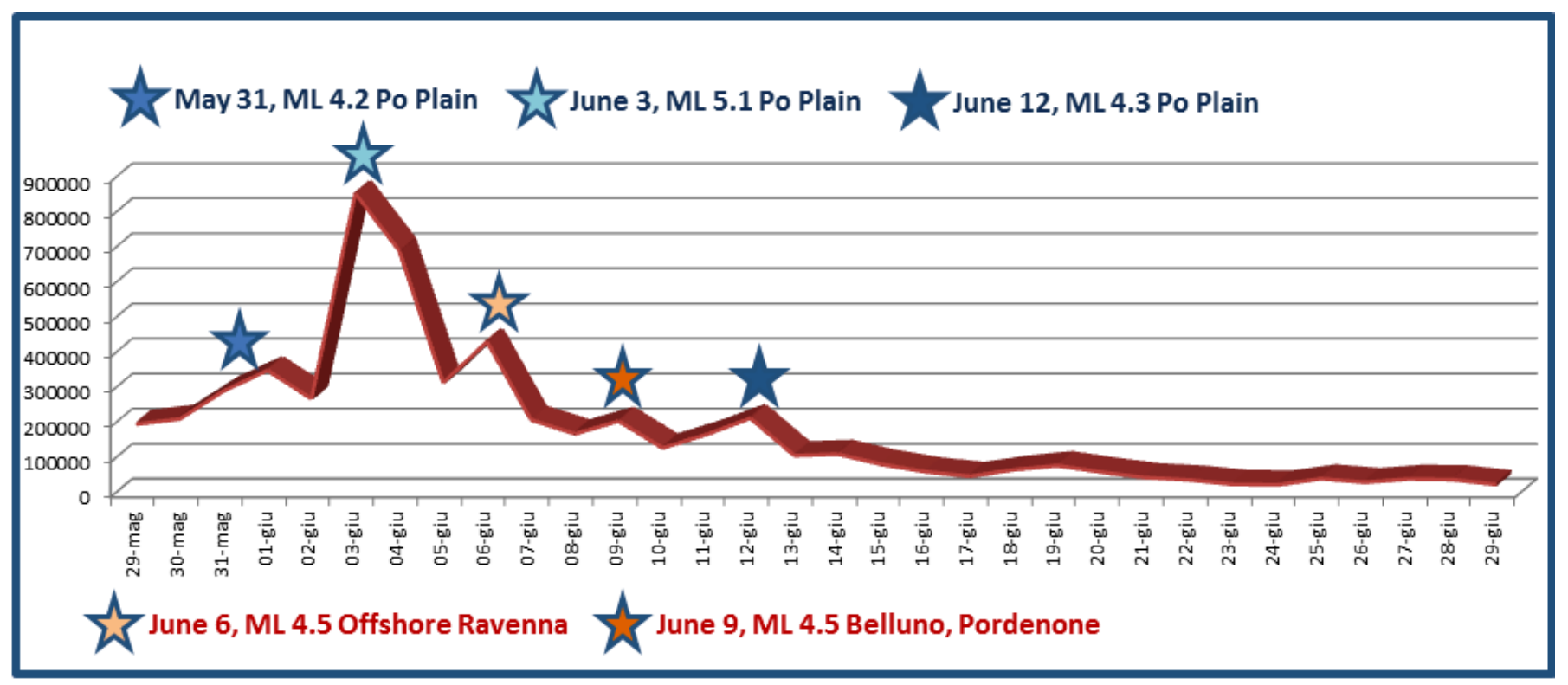

Figure 2. The number of daily contacts during the first month (May 29 to June 29, 2012). Stars: the May 31, 2012, M 4.2 Po Plain event; the June 3, 2012 , $M_{L}$ 5.1 Po Plain event; the June 12, 2012, $M_{L} 4.3$ Po Plain event; the June 6, 2012, $M_{L} 4.5$ event offshore of Ravenna; and the June 9, $2012, M_{L} 4.5$ event along the Alpine southern front, between Belluno and Pordenone.

offshore of Ravenna (Emilia Romagna), and another one on June 9, 2012, along the southern front of the Alps, between Belluno and Pordenone (Veneto). Therefore, we decided to provide information about Italian seismicity by opening new categories in the INGVterremoti blog (besides the one on the Po Plain sequence described above), such as: 'The Pollino sequence' (La sequenza nel Pollino), 'The Italian seismicity' (Sismicità Italia), 'Information' (Informazione), and 'Videos' (Video). In the framework of the blog, we added a series of widgets that WordPress provides: Search, Calendar, Link, Categories, Archives, Recent posts, Top posts, and pages, Top clicks, Twitter, Flickr, Tags, Follow blog, RSS.

At the top of the Home Page of the blog, we added the 'Social Icons' relative to the INGVterremoti YouTube channel, the Flickr INGV archive, the INGVterremoti Twitter

\begin{tabular}{ll}
$\begin{array}{l}\text { The Po Plain earthquake } \\
\text { sub-categories (numbers of posts) }\end{array}$ & $\begin{array}{l}\text { The Po Plain earthquake } \\
\text { sub-categories, in Italian }\end{array}$ \\
\hline Update on seismicity (52) & $\begin{array}{l}\text { Aggiornamento sismicità } \\
\text { Animazioni }\end{array}$ \\
Animations (4) & Approfondimento scientifico \\
Scientific deepening (2) & Deformazione \\
Deformation (6) & Pericolosità sismica \\
Seismic hazard (1) & Rete sismica mobile \\
Mobile seismic network (1) & Rilievi geologici \\
Geological surveys (5) & Rilievi macrosismici \\
Macroseismic surveys (4) & Storia sismica \\
Earthquake history (1) &
\end{tabular}

Table 1. The nine subcategories of 'The Po Plain earthquakes in Emilia' (I terremoti della Pianura Padana Emiliana) INGVterremoti blog. feeds, and the RSS of the blog. Through the Follow blog widget, which is a function that allows people to receive an e-mail as soon as a new posts is published, we had more than 1,000 followers (updated to September 1, 2012), which contributed to the disseminate of the information.

\section{Statistics}

Soon after being published, the blog was found on the web by people looking for information about the Po Plain seismic sequence, and it was viewed by several thousand people. In the first two months (May 29 to July 29, 2012), we recorded more than six million contacts $(6,403,843)$, most of which were concentrated in the first 15 days, with highs and lows in response to the relevant seismic events both for the Po Plain and for elsewhere in Italy. On May 29, 2012, the first day of publication on line, the remarkable reactivation of the sequence with three earthquakes of magnitudes $>5.0$ in the morning led the number of contacts to over 200,000 for a few hours after the opening, even before the blog was linked to the INGV home page (http://www.ingv.it). In the following days, the number of visits increased continuously, also due to the link from the INGV home page. The peak in the number of visits, which was more than 857,000 in a single day, was registered on June 3, 2012, following a $\mathrm{M}_{\mathrm{L}} 5.1$ earthquake in the Po Plain region. It is interesting to note that from June 2 (an Italian holiday) to June 3, 2012, there was an increase of more than 700,000 contacts. Since June 3, 2012, the number of contacts has been decreasing almost constantly, except for some relevant earthquakes that occurred in other regions of Italy, as for the June 6 and June 9, 2012, seismic events (Figure 2).

From May 29 to June 29, 2012, the blog had a total of $5,700,000$ visits, and the average daily number of contacts 


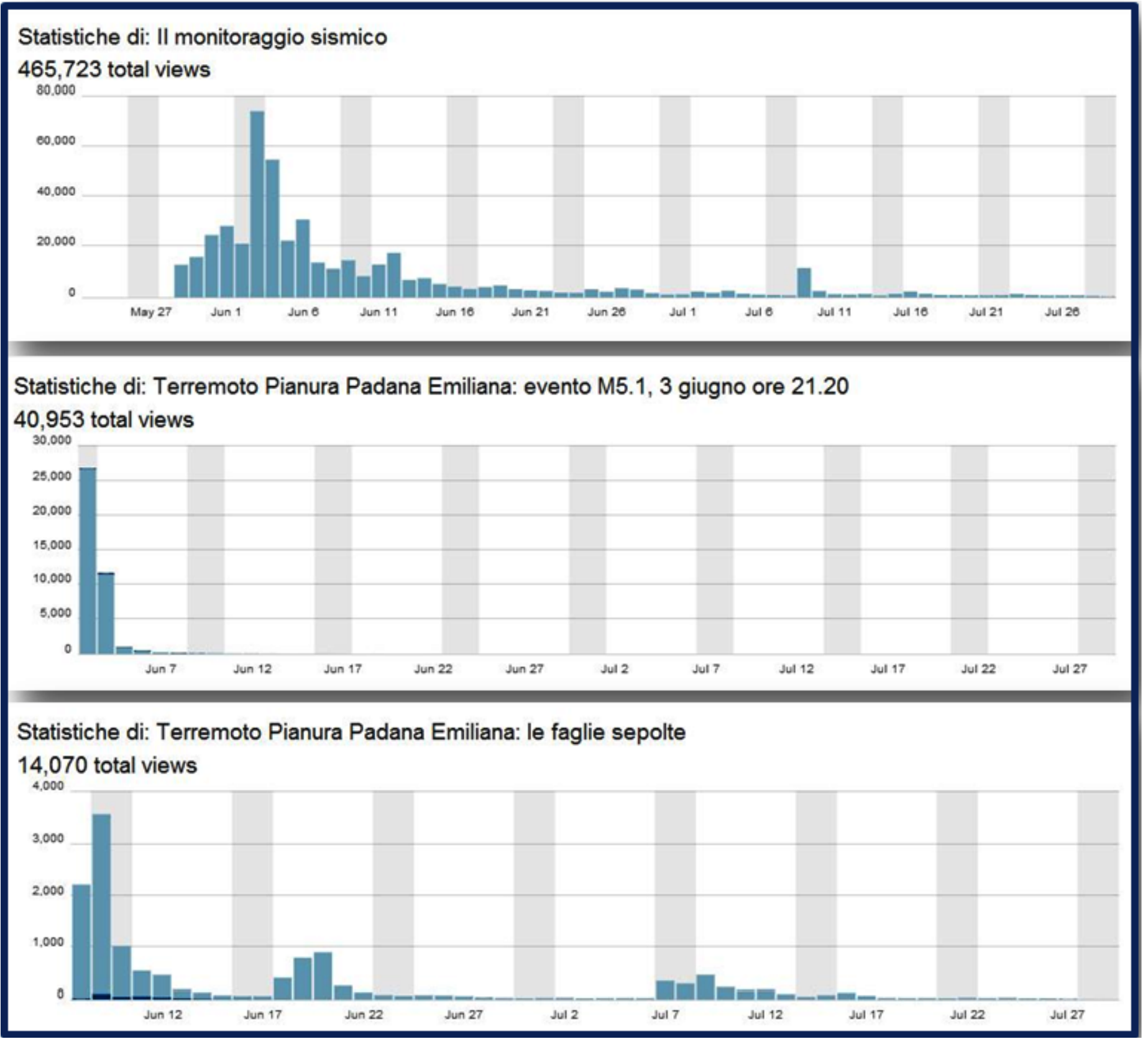

Figure 3. (a) The number of daily contacts of the static page 'Seismic monitoring' (Il monitoraggio sismico), during the first two months (May 29 to July 29 , 2012). (b) The number of daily contacts of the post published soon after the June 3, 2012, $M_{L} 5.1$ earthquake in the Po Plain region. On that day, there was the peak in the number of visits, which was more than 857,000. (c) The number of daily contacts of the post 'Buried faults' (Le faglie sepolte), which was published on June 8, 2012. This post represents in-depth news.

was about 190,000. During the second month (June 30 to July 29,2012$)$ the blog had about 670,000 contacts, with the average number of daily visits of about 22,000 . The peak in the number of visits, as more than 100,000 in a single day, was registered on July 9, 2012, following a $\mathrm{M}_{\mathrm{L}} 3.5$ earthquake in the Alban Hills region, which was felt in Rome. This huge difference of contacts between the first and the second month was due to the trend of seismicity in the Po Plain, which had a strong decrease in both the daily number of earthquakes and their magnitude. This trend in the number of daily visits during the two months of the blog shows the enormous demand for information as soon as an earthquake is felt by the population.
Looking at the statistics (Figure 3a) of one of the static pages, 'Seismic monitoring' (Il monitoraggio sismico), during the first two months (May 29 to July 29), it is easy to note that a static page has a long life, even if it has some highs and lows and some peaks. The number of daily contacts of the post published soon after the June 3, 2012, $\mathrm{M}_{\mathrm{L}} 5.1$ earthquake in the Po Plain region (Figure $3 \mathrm{~b}$ ) had a peak in the number of daily visits (more than 857,000 ) and decreased very rapidly after a few days after its publication, because people lose interest in the news.

Looking at the statistics of other posts relating to some scientific insights (Figure 3c), namely the video on 'The Po Plain buried faults' (Le faglie sepolte in Pianura Padana), we 
note that when an earthquake happens, people seek both information about it and also in-depth news. Indeed, since that post was published (June 8,2012 ) it has been seen by over 14,000 people: most of the readings are relative to a few days after it was posted, but there were also some readings on the days between July 7 and 17, 2012, with a peak on July 9, 2012, the day of the earthquake in the Alban Hills. The video on the buried faults has been viewed more than 60,000 times on the YouTube channel.

It is of note that $95 \%$ of the contacts are from Italy, although there are $5 \%$ from foreign countries. The first three countries are: UK, Germany and the USA. We note that most of the visits occurred through the site www.ingvit (58\%), and the remaining part from other sites, such as institutional sites, search engines, and social media. Today, the blog has on average between 10,000 and 15,000 contacts every day.

\section{Concluding remarks}

This report emphasizes both the pressing request for qualified and comprehensible information by the general public, especially during the most critical stages of a long seismic sequence, and the quick responses by the INGV to such requests immediately after the May 20, 2012, earthquake in the Po Plain, as the research institute that is responsible for seismic monitoring of the Italian territory. We believe that the availability of continuous and timely information is fundamental for the population living through an earthquake experience, as well as for the general public, and for this reason, this represents a crucial task for our Institute.

At the same time, scientifically correct information, that is fast and constantly updated, and is distributed throughout the territory can counter bad information, and can also fight rumors. Indeed, according to Crescimbene et al. [2012], to fight rumors and to disseminate accurate scientific information, it is essential to go in two directions: there must be the promotion of quality science journalism, and scientists must be trained to engage in communication and dissemination of scientific information. We are trying to work in this direction.

The experience during the Po Plain sequence showed us that as well as the classical information released through our web sites, the blog structure is suitable for fast, constantly updated, and scientifically correct information. Indeed, it allowed us easier and quicker publication of updates and results, and the use of a simpler language of communication.

Although we had to close the comments section due to the impossibility of answering the questions and requests during the emergency, we received many e-mails and interesting feedback, thanks to which we have modified and improved the blog. Because of the innovative features of the blog, and because of its success that can be seen by the statistics on the number of accesses to its pages, the blog can be considered one of the first interactive tools of mass communication in Italy between a great institute of scientific research and the general public. This blog not only provides timely updates of Italian seismicity, but it also includes reports of ongoing seismic activity, and disseminates the basics of seismology, of which there is also a great demand from the public, as shown by the high number of contacts with the static pages of the blog.

We also think the blog has had a positive effect on some media (newspapers, magazines, broadcasters and news agencies), whereby having qualified information directly from researchers of the INGV avoided inaccuracies due to the transfer chain of information (from source to end user, through the medium of the press agencies), and approximations and inaccuracies that can arise due to the distorted interpretation of hastily granted and gathered interviews.

Further research might include an in-depth analysis of audience behavior: to assess the effectiveness of a blog, the number of contacts is surely the main indicator, but nevertheless, other indicators can be taken into account (e.g., navigation strategies: how do user find/access the blog; how many posts do they read during each session; how do they move inside the blog; where do users come from: considering the area they come from - not only the country to understand if the blog reaches a broader audience or if it is limited to the population shaken by the earthquakes; page views; time spent on each post; platform used to access the blog: computer vs. mobile). Moreover, users can also be invited to respond to an ad-hoc survey to monitor their satisfaction and their further needs. Both strategies can also provide useful material to further improve this blog. A broader research project might also include crossmedia comparisons, taking into account the whole set of social media used by the INGV (YouTube, Twitter, Facebook, Flickr, Apple).

Future developments include the creation of new categories and new articles for other regions of Italy, and in-depth scientific articles to explain the results of research activities. We also wish to increase the FAQ (Frequently Asked Questions) section, and to add an English version of the blog. We also plan to find a way to implement the interaction with the public, through answering questions and comments.

This blog was designed and published immediately after the earthquake of May 20,2012, and it is an innovative tool to provide information to people, not only during a seismic sequence, but also 'in times of peace', thus contributing to the work of prevention, which remains the best defense against earthquakes and the only way to reduce their effects.

Acknowledgements. We thank all our colleagues who have contributed to this initiative, and who have written articles and provided scientific material. Thanks to Giuliana D'Addezio, Franco Foresta Martin and an anonymous reviewer for comments that improved this manuscript. 


\section{References}

Amato, A., L. Arcoraci, E. Casarotti, R. Di Stefano and the INGVterremoti team (2012). The INGVterremoti channel on YouTube. Annals of Geophysics, 55 (3), 403-408; doi:10.4401/ag5546.

Bruns, A., J. Burgess, K. Crawford and F. Shaw (2012). \#qldfloods and@QPSMedia: Crisis communication on Twitter in the 2011 south-east Queensland floods, Brisbane, ARC Centre of Excellence for Creative Industries and Innovation; http: / / cci.edu.au/floodsreport.pdf

Crescimbene, M., F. La Longa and T. Lanza (2012). The science of rumors, Annals of Geophysics, 55 (3), 421-425; doi:10.4401/ag-5538.

Earle, P.S., D.C. Bowden and M. Guy (2011). Twitter earthquake detection: earthquake monitoring in a social world, Annals of Geophysics, 54 (6), 708-715; doi:10.4401/ ag-5364.

Moretti, M., C. Nostro, A. Govoni, M. Pignone, F. La Longa, M. Crescimbene and G. Selvaggi (2011). L'intervento del Centro Operativo Emergenza Sismica in occasione del terremoto del 2009 a L'Aquila, Quaderni di Geofisica, 92, INGV, 29 pp.

Nostro, C., A. Amato, G. Cultrera, L. Margheriti, G. Selvaggi, L. Arcoraci, E. Casarotti, R. Di Stefano, S. Cerrato and the May 11 Team (2012). Turning the rumor of the May 11,2011 , earthquake prediction in Rome, Italy, into an information day on earthquake hazard, Annals of Geophysics, 55 (3), 413-420; doi:10.4401/ag5559.

\footnotetext{
${ }^{\star}$ Corresponding author: Alessandro Amato, Istituto Nazionale di Geofisica e Vulcanologia, Centro Nazionale Terremoti, Roma, Italy; email: alessandro.amato@ingv.it. 